\title{
Induction of hairy roots by various strains of Agrobacterium rhizogenes in different types of Capsicum species explants
}

\author{
Nursuria Md Setamam ${ }^{1 *}$, Norrizah Jaafar Sidik ${ }^{1 *}$, Zainon Abdul Rahman ${ }^{1 *}$ and Che Radziah Che Mohd Zain ${ }^{2^{*}}$
}

\begin{abstract}
Background: Capsicum annuum and Capsicum frutescens, also known as "chilies", belong to the Solanaceae family and have tremendous beneficial properties. The application of hairy root culture may become an alternative method for future development of these species by adding value, such as by increasing secondary metabolites and improving genetic and biochemical stability compared with normal Capsicum plants. Therefore, in this research, different types of explants of both species were infected with various Agrobacterium rhizogenes strains to provide more information about the morphology and induction efficiency of hairy roots. After 2 weeks of in vitro seed germination, young seedling explants were cut into three segments; the cotyledon, hypocotyl, and radical. Then, the explants were co-cultured with four isolated A. rhizogenes strains in Murashige \& Skoog culture media (MS) containing decreasing carbenicillin disodium concentrations for one month.

Results: In this experiment, thick and short hairy roots were induced at all induction sites of $C$. annuum while thin, elongated hairy roots appeared mostly at wound sites of $C$. frutescens. Overall, the hairy root induction percentages of $C$. frutescens were higher compared with $C$. annuum. Hairy root initiation was observed earliest using radicles ( $1^{\text {st }}$ week), followed by cotyledons ( $2^{\text {nd }}$ week), and hypocotyls ( $3^{\text {rd }}$ week). Cotyledon explants of both species had the highest induction frequency with all strains compared with the other explants types. Strains ATCC 13333 and ATCC 15834 were the most favourable for C. frutescens while ATCC 43056 and ATCC 43057 were the most favourable for $C$. annuum. The interactions between the different explants and strains showed significant differences with $p$-values $<0.0001$ in both Capsicum species.
\end{abstract}

Conclusions: Both Capsicum species were amenable to A. rhizogenes infection and hairy root induction is recommended for use as an alternative explants in future plant-based studies.

Keywords: Capsicum annuum, Capsicum frutescens, Agrobacterium rhizogenes, Hairy root culture, Hairy root induction, Explant type

\section{Background}

Capsicum annuum and Capsicum frutescens also known as "chilies" belong to the Solanaceae family [1]. These species have tremendous economic value as vegetables crops and medicinal plants in numerous countries. Capsicum species have multiple usages as medicinal drugs

\footnotetext{
* Correspondence: nursuriasetamam@yahoo.com; norri536@salam.uitm.edu; zainon981@salam.uitm.edu; cradziah@ukm.my

${ }^{1}$ Faculty of Applied Sciences, Universiti Teknologi MARA, 40450 Shah Alam, Selangor, Malaysia

${ }^{2}$ Faculty of Science and Technology, Academic Centre of Bioscience and Biotechnology, Universiti Kebangsaan Malaysia, 43600 Bangi, Selangor, Malaysia
}

\section{Biomed Central}

(c) 2014 Md Setamam et al.; licensee BioMed Central Ltd. This is an Open Access article distributed under the terms of the Creative Commons Attribution License (http://creativecommons.org/licenses/by/2.0), which permits unrestricted use, distribution, and reproduction in any medium, provided the original work is properly credited. for various diseases because of their analgesic, antiinflammatory, antioxidant and anticancer properties $[2,3]$. These beneficial properties of Capsicum species usually come from their major secondary metabolites such as capsaicinoids, capsinoids, quercetin and luteolin [4-7]. Currently, one of the developing trends is hairy root culture techniques that enable high production of these secondary metabolites for extensive industrial applications [8-10].

In recent years, hairy root culture has been chosen as an alternative method for the development of crops and medicinal plants such as Capsicum species because of its many advantages $[11,12]$. Hairy root cultures have been 


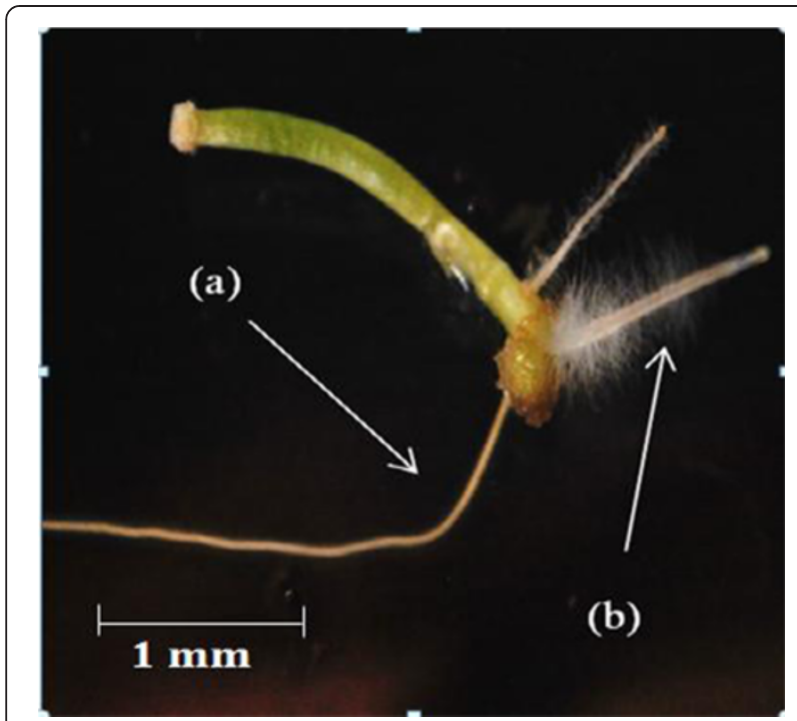

Figure 1 Different root morphologies from explants of Capsicum spp. co-cultured with $A$. rhzogenes; (a) normal root, (b) hairy root.

proven to increase secondary metabolite levels in various plants including Capsicum species for industrial purposes $[8,13,14]$. Another advantage is the improvement of the plant system with better genetic and biochemical stability compared with normal plants [15-17].
One of the main factors that contribute to achieving hairy root induction is the type of explant used. Several studies on hairy roots in Capsicum species have used various explants such as hypocotyls [18], cotyledons [19], leaves [20] and mesophyll protoplasts [21]. In this research, different types of explants of both $C$. annuum and $C$. frutescens were infected with various $A$. rhizogenes strains. The objective of this research was to provide information on the establishment of hairy roots for both $C$. annuum and $C$. frutescens in term of morphology and induction efficiency.

\section{Results and discussion}

\section{Effect on morphology of hairy root induction}

In this experiment, young seedlings of $C$. annuum and C. frutescens germinated in vitro were used as study plants. Three types of explants-cotyledon, hypocotyl, and radical-from each Capsicum species were cocultured with four isolated $A$. rhizogenes wild type strains (ATCC 15834, ATCC 43056, ATCC 13333, and ATCC 43057). After 1 month, hairy roots were induced by all A. rhizogenes strains for all explants types in both Capsicum species.

The successfully induced hairy roots of both Capsicum species appeared as whitish fungus needle-like structures (Figure 1b) compared with normal roots, which can be

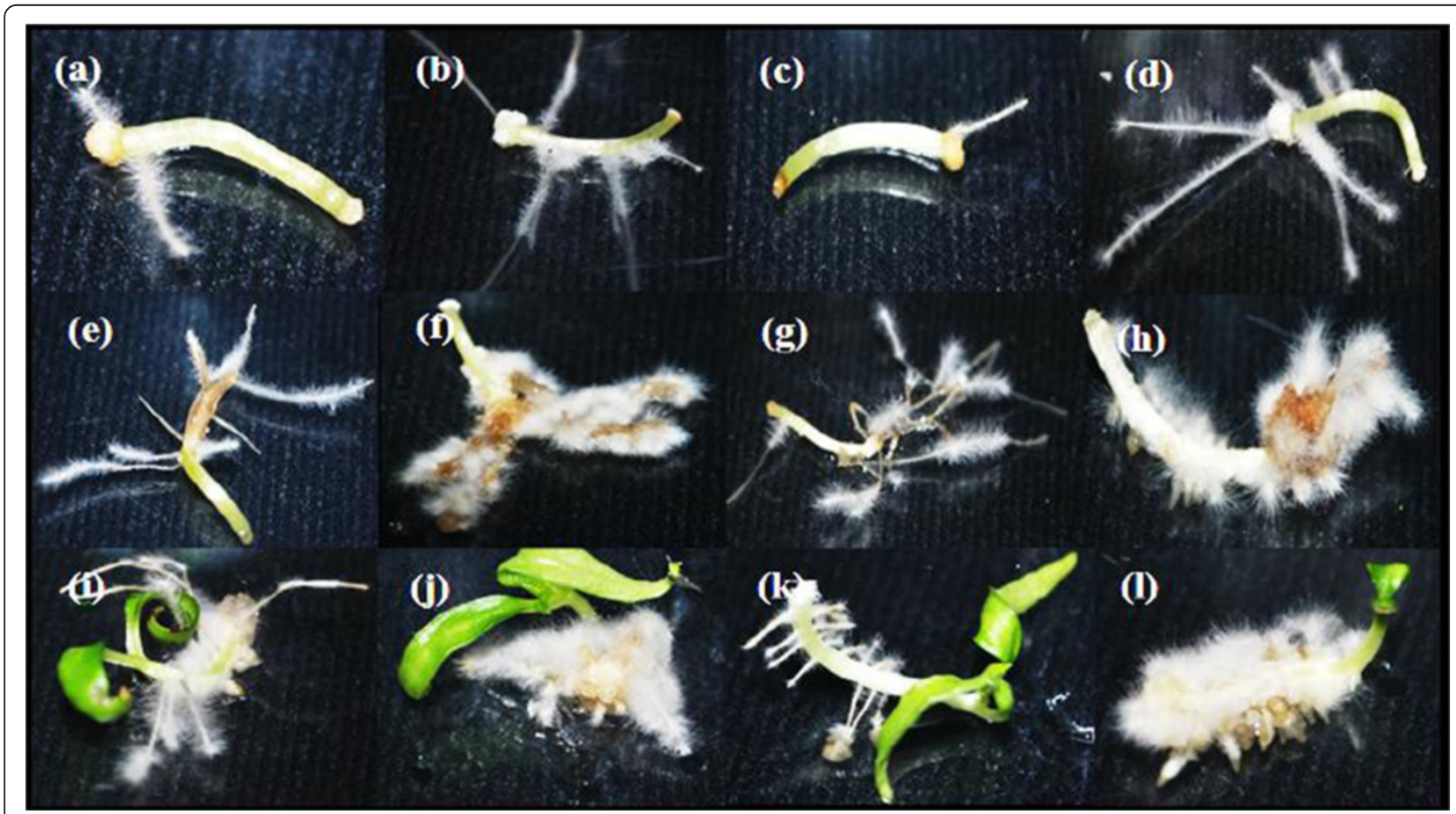

Figure 2 Capsicum annuum explants co-cultured with different Agrobacterium rhizogenes strains for one month. (a) Hypocotyl with ATCC 15834, (b) hypocotyl with ATCC 43056, (c) hypocotyl with ATCC 13333, (d) hypocotyl with ATCC 43057, (e) radicle with ATCC 15834, (f) radicle with ATCC 43056, (g) radicle with ATCC13333, (h) radicle with ATCC 43057, (i) cotyledon with ATCC 15834, (j) cotyledon with ATCC 43056, (k) cotyledon with ATCC13333 and (I) cotyledon with ATCC 43057. 


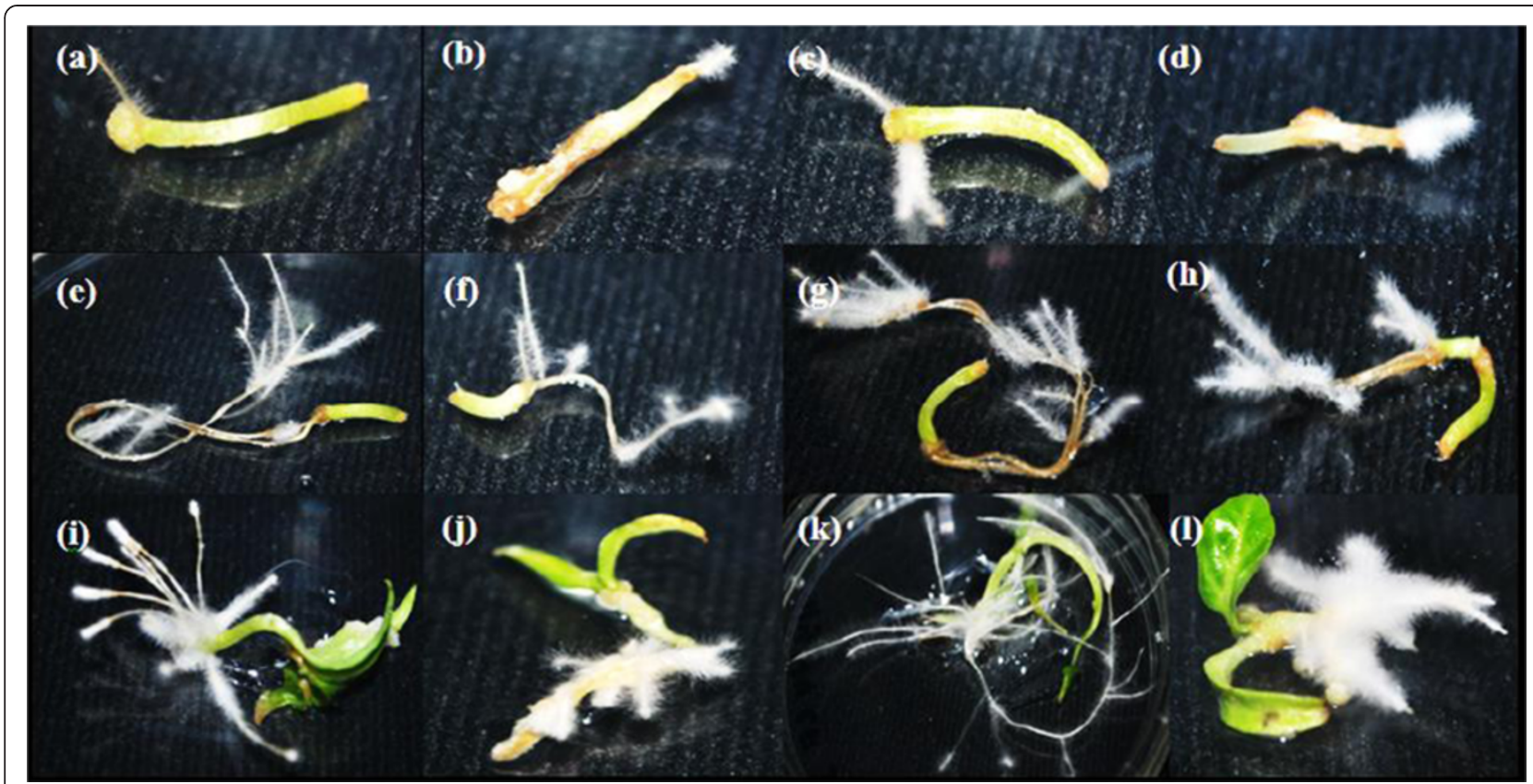

Figure 3 Capsicum frutescens explants co-cultured with different $\boldsymbol{A}$. rhizogenes strains for 1 month. (a) Hypocotyl with ATCC 15834, (b) hypocotyl with ATCC 43056, (c) hypocotyl with ATCC 13333, (d) hypocotyl with ATCC 43057, (e) radicle with ATCC 15834, (f) radicle with ATCC 43056, (g) radicle with ATCC13333, (h) radicle with ATCC 43057, (i) cotyledon with ATCC 15834, (j) cotyledon with ATCC 43056, (k) cotyledon with ATCC13333 and (I) cotyledon with ATCC 43057.

described as yellowish long rods with a smooth surface (Figure 1a). The normal roots of both Capsicum species appeared to follow geotropic patterns but the hairy roots showed a plagiotropic response. The plagiotropic growth of hairy roots in plants is possibly due to the lack of amyloplasts in the starch grains of hairy roots. Sensory balance receptors called statoliths lead to the diverse hairy root growth directions $[22,23]$.

The induced hairy roots of both Capsicum species were similar in terms of structure, colouration, and growth pattern in each treatment. However, the length, thickness, and induction site varied depending on the type of strain and explant used. Thick and short hairy roots appeared on radicle and cotyledon explants treated with ATCC 43056 and ATCC 43057 in C. annuum (Figure 2), while all explants of $C$. frutescens showed thin, elongated hairy roots except in cotyledon explants treated with ATCC 43056 and 43057 (Figure 3).

Wound sites are a common location for hairy root induction since they serve as a genetic transfer point for A. rhizogenes $[24,25]$. In hypocotyl explants of both species, hairy roots were induced at the wound site except for hypocotyls of C. annuum with ATCC 43056 and ATCC 43057 (Figure 2). However, in radicle explants of both species, hairy roots were only induced far from the wound sites with the exception of $C$. annum with ATCC

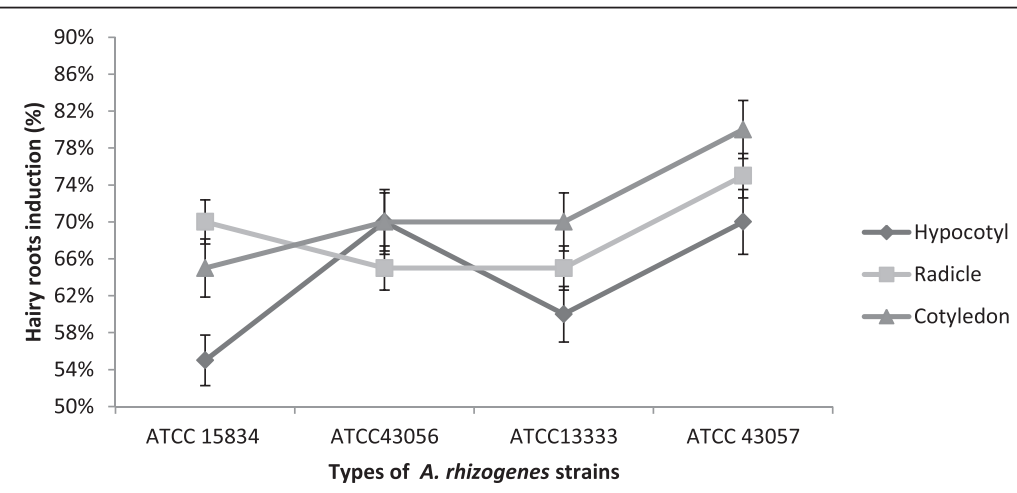

Figure 4 Percentages of hairy root induction per total explants $(n=20)$ of Capsicum annuum after 1 month. 


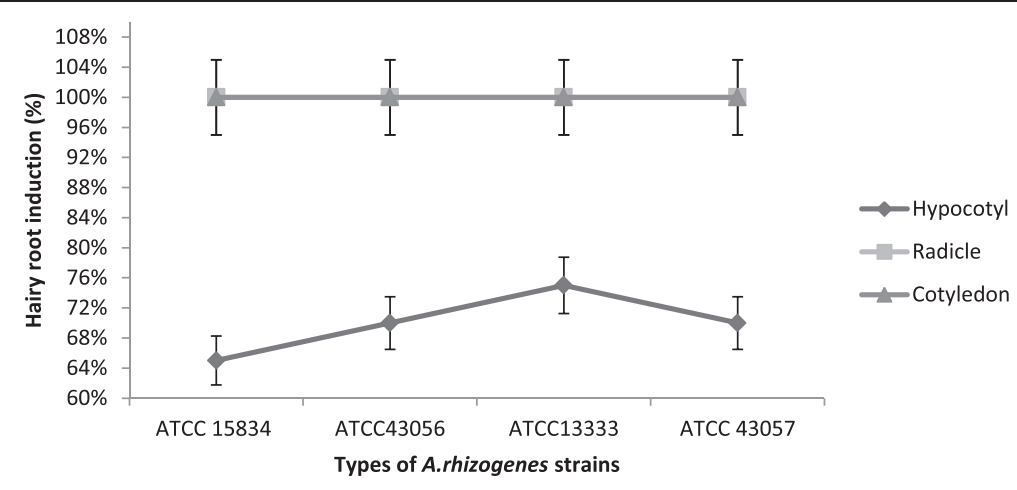

Figure 5 Percentages of hairy root induction per total explants $(n=20)$ of Capsicum frutescens after 1 month.

13333 and ATCC 43057 (Figure 2). Additionally, hairy roots were induced at the wound sites of $C$. frutescens cotyledon explants by all strains (Figure 3 ).

The formation of callus in plant cultures is usually caused by additional plant hormones present in the medium. However, in hairy root cultures, the active expression of rol genes due to the presence vir genes on the $A$. rhizogenes $R i$-plasmid may cause extreme synthesis of endogenous auxin and cytokinin in the host cells [26]. This may lead to the production of both hairy roots and callus simultaneously [27]. In our experiment, $C$. аnnuum was able to produce both callus and hairy roots at the same time, in contrast to $C$. frutescens. Both hypocotyl and radicle explants of $C$. annuum with strains ATCC 43056 and ATCC 43057 (Figure 2) were able to establish whitish, soft-textured callus at the wound sites. C. annuum treated with ATCC 15834 and ATCC 13333 (Figure 3) also produced callus at the wound sites of cotyledon explants.

Direct co-culturing with $A$. rhizogenes strains can result in bacteria residing in the plant cells $[28,29]$. However, active infection can cause cells to rupture and cell death known as necrosis. In in vitro cultures, the remaining necrotic cells may secrete phenolic compounds and fungal avirulence proteins that are highly toxic [30]. The presence of necrosis and antibiotics also may affect hairy root induction and contamination in samples [31,32].

\section{Effect on hairy root induction}

In this experiment, three parameters were used to estimate the hairy root induction efficiencies of both $C$. annuum and $C$. frutescens. These parameters were hairy root induction percentage per total explants, hairy root initiation days per total explants and hairy root induction frequency per single explant.

Overall, the results showed that the hairy root induction percentages of $C$. frutescens were higher compared with $C$. annuum. Hypocotyl explants for both Capsicum species showed induction percentages of $55-75 \%$ with all strains. The mean percentages for $C$. frutescens radicle and cotyledon explants with all strain types were the highest at $100 \%$ hairy root induction.

The radicles and cotyledons of $C$. annuum showed less hairy root induction with percentages between $65 \%$ and $80 \%$ for all strains. Cotyledon explants of C. аnпииm with ATCC 43057 had the highest induction rate at $80 \%$ (Figures 4 and 5). These results demonstrate that both explant type and species play a role in hairy root induction.

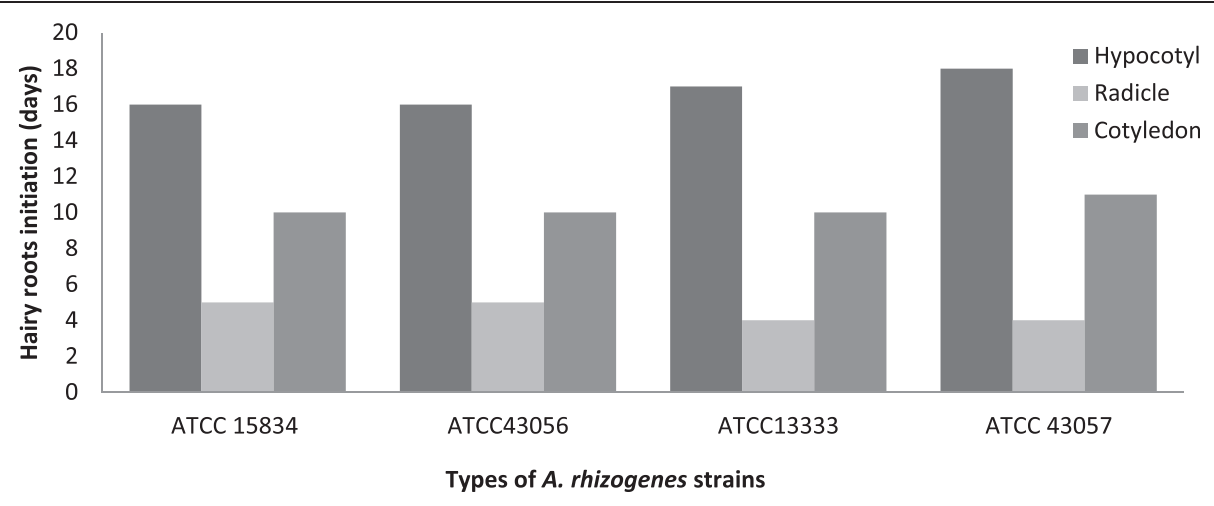

Figure 6 Hairy root initiation (days) per total explants $(n=20)$ of Capsicum annum after 1 month. 


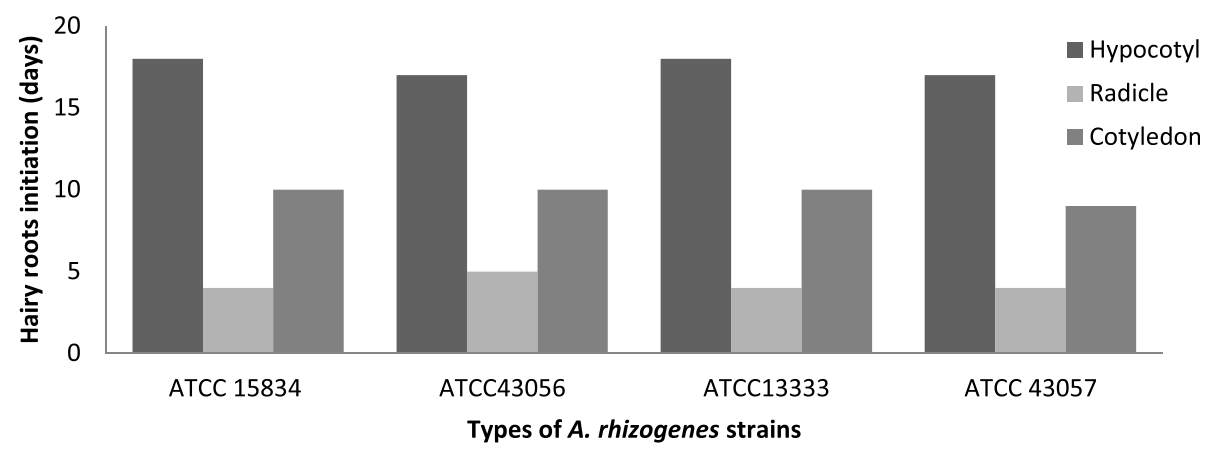

Figure 7 Hairy root initiation (days) per total explants $(n=20)$ of Capsicum frutescens after 1 month.

This may be because each species expresses rol genes differently [25,33].

The earliest hairy root induction occurred within a week from a radicle of $C$. frutescens treated with ATCC 43057, while the longest period of time for hairy root induction was 18 days from hypocotyl explants with all strain treatments for both Capsicum species (Figures 6 and 7). The earliest hairy root initiation was observed in ascending order in radicles ( $1^{\text {st }}$ week), cotyledons $\left(2^{\text {nd }}\right.$ week), and hypocotyls ( $3^{\text {rd }}$ week). This was because of the properties of both radical and cotyledon explants, which consist of meristematic cells that are highly active in cell division [34,35].

Hairy roots were induced faster from radicle explants than cotyledon explants in both species. This is because of the ability of the radicle to initiate pericycle cells around the root for greater hairy root establishment. The cotyledon explants in both species had slower initiation times because the meristematic cells specifically accentuate the formation of new leaves and axillary buds [35].

The hypocotyl explants of $C$. annuum and C. frutescens in all strain treatments had the highest hairy roots initiation times (Figures 6 and 7), which may have been due to lower cell division activities. These inactive cells may require more time to regulate the cell toward decisive factors such plant hormones, turgor pressures and cyclic-dependent kinases (CDKs) for cell expansion and differentiation [36,37]. Therefore, hairy root initiation was deferred up to the third week.

In this study, the number of hairy roots present in a single explant was expressed as the frequency of hairy root induction. Cotyledon explants of both species had the highest frequency with all strains compared with other explant types. The highest frequency recorded was for cotyledon explants of $C$. frutescens with ATCC 15834 at $15.75 \pm 0.67$. The ATCC 15834 strain also showed the highest frequency in both hypocotyl and radicle explants of $C$. frutescens with $1.70 \pm 0.53$ and $7.75 \pm 0.85$, respectively (Table 1). However, ATCC 15834 showed the lowest induction frequency in hypocotyl, radicle, and cotyledon explants of $C$. annuum with $1.40 \pm 0.47,12.05 \pm 0.61$ and $12.80 \pm 0.79$, respectively. ATCC 1333 showed the second lowest values after ATCC 15834 compared with the other strains (ATCC 43056 and ATCC 43057) with $2.15 \pm 0.90$, $10.32 \pm 0.96$ and $13.50 \pm 0.49$ (Table 1). These results showed that the induction frequencies of $C$. annuum were lower with ATCC 13333 and ATCC 15834 for all explant types while $C$. frutescens had relatively higher frequencies.

Thus, we concluded that ATCC 13333 and ATCC 15834 were the most favourable for $C$. frutescens, while ATCC 43056 and ATCC 43057 were the most favourable for C. annuum. The most suitable explants for a high frequency of hairy root induction in C. annuum and

Table 1 Hairy root induction frequency per single explant (mean \pm standard deviation) in both Capsicum spp. after 1 month

\begin{tabular}{llllll}
\hline List of species & $\begin{array}{l}\text { Explant } \\
\text { type }\end{array}$ & Strain & & \\
\cline { 2 - 5 } & ATCC 13333 & ATCC43056 & ATCC15834 & ATCC 43057 \\
\hline Capsicum annuum & Hypocotyl & $2.15 \pm 0.90$ & $2.45 \pm 0.63$ & $1.40 \pm 0.47$ & $12.05 \pm 0.61$ \\
\cline { 2 - 6 } & Radicle & $10.32 \pm 0.96$ & $13.20 \pm 0.78$ & $12.80 \pm 0.79$ & $13.35 \pm 0.58$ \\
\cline { 2 - 6 } & Cotyledon & $13.50 \pm 0.49$ & $14.05 \pm 0.46$ & $1.70 \pm 0.53$ & $13.8 \pm 0.96$ \\
\hline Capsicum frutescens & Hypocotyl & $1.55 \pm 0.68$ & $1.15 \pm 0.96$ & $7.75 \pm 0.85$ & $7.00 \pm 0.50$ \\
\cline { 2 - 6 } & Radicle & $7.50 \pm 0.69$ & $6.75 \pm 0.47$ & $15.75 \pm 0.67$ & $9.45 \pm 0.51$ \\
\cline { 2 - 5 } & Cotyledon & $10.30 \pm 0.82$ & $7.70 \pm 0.93$ & & \\
\hline
\end{tabular}


Table 2 Two-way ANOVA $(\alpha=0.05)$ for hairy root induction frequency per single explant of Capsicum annum after 1 month

\begin{tabular}{llllll}
\hline Source of variation & Sum of squares (SS) & Degree of freedom (DF) & Mean square (MS) & F-statistic & Significant level (p-value) \\
\hline A: Types of explants & 5944.633333 & 2 & 2972.316667 & 27.47 & 0.0001 \\
\hline B: Types of strains & 86.512500 & 3 & 28.837500 & 0.27 & 0.8495 \\
\hline A $\times$ B & 6031.14583 & 5 & 1206.22917 & 11.15 & 0.0001 \\
\hline Error & 25318.65000 & 234 & 108.19936 & & \\
\hline Corrected total & 31349.79583 & 239 & & & \\
\hline
\end{tabular}

C. frutescens were the cotyledon and radicle. The explant types in C. annuum and C. frutescens showed interactions affecting the frequency of hairy roots per single explant with highly significant differences, with $p<0.0001<<0.05$ (Tables 2 and 3 ). The different strains showed no significant differences in $C$. annuum ( $p$-value $=0.8495>0.05$ ) (Table 2) but had significant differences in C. frutescens, with $p<0.0001$ (Table 3 ). The interactions between the different explant types and the different strains showed significant differences with $p$-values $<0.0001$ in both Capsicum species (Tables 2 and 3). Therefore, the interactions between both explant type and bacterial strain can affect the frequency of hairy roots per single explant in both Capsicum species.

\section{Conclusions}

In this study, both $C$. annuum and $C$. frutescens were amenable to $A$. rhizogenes infection. Both species showed positive responses, yielding hairy roots without the presence of exogenous plant hormones. These hairy roots exhibited whitish, fungus needle-like structures and plagiotropic growth similar to those in other plant studies. However, morphological variations were still seen between the two species in terms of length, thickness and the site of hairy root induction. Variations in species, strain and explant type led to different hairy root induction efficiencies. C. annuum was more amenable to ATCC 43056 and ATCC 43057 compared with ATCC 15834 and ATCC 13333, while C. frutescens was more amenable to ATCC 15834 and ATCC 13333 compared with ATCC 43056 and ATCC 43057. Despite the antagonistic response demonstrated by these two species, the various explant types showed similar results. In ascending order, the most suitable explant types for maximum hairy root induction were cotyledons, radicles and hypocotyls. Overall, our results suggest that hairy root induction could be used for alternative explants in future plant-based studies such as plant regeneration, somatic embryogenesis, molecular analysis or phytochemical studies.

\section{Method}

Seed sterilization and in vitro seed germination

Seeds of C. annuum var. cayenne pepper and C. frutescens var. bird's eye chili were obtained from a local supplier. The seed edges were cut approximately $1 \mathrm{~mm}$ before soaking them in sterilised water for a day. Then, the seeds were washed under tap water for 5 minutes before the seed surfaces were sterilised in 15\% sodium hypochlorite $(\mathrm{NaClO})$ with two drops of Tween 80 for 10 minutes. The seeds were then rinsed twice with sterile water before being sterilised with $70 \%$ ethanol for 3 minutes. Finally, the seeds were rinsed again several times with sterile water. Ten sterilised seeds were cultured in individual Petri dishes that contained half-strength MS solid media. The seeds were left to germinate under a 16/8 h (light/dark) photoperiod for two weeks.

\section{Culture medium preparation}

Full-strength MS medium was prepared by adding $4.4 \mathrm{~g}$ of MS powder, $1 \mathrm{~g}$ myo-inositol, and $30 \mathrm{~g}$ sucrose to $1 \mathrm{~L}$ of sterile distilled water. The solution $\mathrm{pH}$ was adjusted to approximately 5.7 to 6.0 using hydrochloric acid $(\mathrm{HCl})$ or sodium hydroxide $(\mathrm{NaOH})$. About 4 g gelrite was added to the medium before autoclaving at $121^{\circ} \mathrm{C}$

Table 3 Two-way ANOVA ( $a=0.05$ ) for hairy root induction frequency per single explant of Capsicum frutescens after 1 month

\begin{tabular}{llllll}
\hline Source of variation & Sum of squares (SS) & Degree of freedom (DF) & Mean square (MS) & F-statistic & Significant level (p-value) \\
\hline A: Types of explants & 3351.308333 & 2 & 1675.654167 & 80.37 & 0.0001 \\
\hline B: Types of strains & 356.016667 & 3 & 118.672222 & 5.69 & 0.0009 \\
\hline A $\times$ B & 3707.325000 & 5 & 741.465000 & 35.56 & 0.0001 \\
\hline Error & 4878.658333 & 234 & & & \\
\hline Corrected total & 8585.983333 & 239 & & & \\
\hline
\end{tabular}


and 15 psi for 20 minutes. Half-strength MS solid medium was prepared similarly but the MS powder, myo-inositol and sucrose amounts were reduced by half.

\section{Preparation of sterile explants and pre-culturing}

After 2 weeks of in vitro seed germination, 20 young seedling explants were cut into three segments (cotyledon, hypocotyl, and radicle) about 7-10 $\mathrm{mm}$ long. The cut segments were pre-cultured in Petri dishes containing halfstrength MS solid medium for 1 day.

\section{Bacterial strains and cultures}

Four wild A. rhizogenes strains (ATCC 15834, ATCC 43056, ATCC 13333 and ATCC 43057) were used for hairy root induction. The isolated strains were cultured in $0.01 \mathrm{~L}$ nutrient broth $(\mathrm{NB})$ medium. The NB culture medium was prepared by weighing out $8 \mathrm{~g} / \mathrm{L} \mathrm{NB}$ powder and transferring it into $1 \mathrm{~L}$ of sterile water. Then, the solution was autoclaved and 0.01Lwas transferred into individual universal bottles. After three days, $10 \mu \mathrm{L}$ of each isolated strain was inoculated into the NB cultures for three more days at a temperature of $26^{\circ} \mathrm{C}$. The bacterial cultures with an optical density (OD) of 500-600 nm were used for co-culture after being shaken at $300 \mathrm{rpm}$ for an hour. For culture preservation, $1 \mathrm{mLeach}$ of the main cultures were kept in $0.009 \mathrm{~L}$ nutrient broth at $10^{-1}$ dilution at a temperature of $26^{\circ} \mathrm{C}$ for not more than 1 week. The unused working cultures were stored in $20 \%$ glycerol and kept frozen in $-20^{\circ} \mathrm{C}$ freezer.

\section{Co-culture and hairy root culture establishment}

Each explant was immersed in $10 \mu \mathrm{L}$ of the isolated strains in Petri dishes containing half-strength MS solid medium for a day. Then, the co-cultured explants were decontaminated using washing medium containing MS liquid medium with carbenicillin disodium $(1 \mathrm{~g} / \mathrm{L})$ for 2 hours. The co-cultured explants were dried with sterile filter paper to remove excess bacteria before culture on full-strength MS solid medium containing $0.5 \mathrm{~g} / \mathrm{L}$ carbenicillin disodium. The explants were sub-cultured each week on MS solid medium containing decreasing carbenicillin disodium concentrations $(0.2,0.1,0.05 \mathrm{mg} / \mathrm{L})$ for 1 month. Explants without $A$. rhizogenes strain treatment were used as controls. The experiments were performed with 20 replications per each treatment $(n=20)$.

\section{Statistical analysis}

The data were collected after one month and analysed using a two-way analysis of variance (ANOVA) with SAS 9.0 and standard deviation mean values expressed as mean \pm SD.

\section{Competing interests}

The authors have no competing interests to declare.

\section{Authors' contributions}

NMS carried out the overall research experiment, was involved in design of the study, performed statistical analysis, acquired and interpreted data, and prepared manuscript. NJS contributed to the overall design of the research study, coordinated the research experiment, and was involved in drafting the manuscript and revising it critically for important intellectual content. ZAR participated in design of the study involving microbiology and revising the manuscript critically for intellectual content. CRCMZ performed bacterial strain culture and was involved in maintaining bacterial culture stocks in the early stages of the research experiment. All authors have read and approved the final manuscript for submission.

\section{Acknowledgements}

The authors are deeply indebted to the Faculty of Applied Science of University Technology Mara, for their research facilities and the Faculty of Science and Technology, Academic Centre of Bioscience and Biotechnology of Universiti Kebangsaan Malaysia for providing Agrobacterium rhizogenes strains. This research study was funded by the Research Management Institute (UiTM) under FRGS/2/ 2010/SG/UiTM/03/22

Received: 25 July 2013 Accepted: 19 June 2014

Published: 30 June 2014

\section{References}

1. Heiser CB, Smith PG: Cultivated Capsicum peppers. Econ Bot 1953, 7(3):214-227.

2. Deal $C L$, Schnitzer TJ, Lipstein E, Seibold JR, Stevens RM, Levy MD: Treatment of arthritis with topical capsaicin: a double-blind trial. Clin Ther 1991, 13(3):383-395

3. Delis M, Garbaczewska G, Niemirowicz-Szczytt K: Differentiation of adventitious budsfrom Capsicum annuum hypocotyls after co-culture with Agrobacterium tumefaciens. Acta Biol Crac 2005, 17:8-193.

4. Chuenkitiyanona S, Vardhanabhutib N, Jianmongkolc S: A potential benefit of quercetin in preserving tight junction integrity. J Epithelial Biol Pharmacol 2012, 5:28-31.

5. Luo XJ, Peng J, Li YJ: Recent advances in the study on capsaicinoids and capsinoids. Euro J Pharmacol 2011, 650(1):1-7.

6. Materska M, Perucka I: Antioxidant activity of the main phenolic compounds isolated from hot pepper fruit (Capsicum annuum L.). J Agric Food Chem 2005, 53:1750-1756.

7. Ruanma K, Shank L, Chairote G: Phenolic content and antioxidant properties of green chili paste and its ingredients. Maejo Int J Sci Technol 2010, 4(2):193-200.

8. Srivastava S, Srivastava AK: Hairy root culture for mass-production of high-value secondary metabolites. Biotechnol Inform Healthcare 2007, 27(1):29-43.

9. Suza W, Harris RS, Lorence A: Hairy roots: from high-value metabolite production to phytoremediation. Electron J Integr Biosci 2008, 3(1):57-65.

10. Swarna J, Ravindhran R: Agrobacterium rhizogenes - mediated hairy root induction of Momordica charantia Linn. and the detection of charantin, a potent hypoglycaemic agent in hairy roots. Res J Biotechnol 2012, 7(4):227-231.

11. Zhu YX, Ou-Yang WJ, Zhang YF, Chen ZL: Transgenic sweet pepper plants from Agrobacterium-mediated transformation. Plant Cell Rep 1996, 16:71-75

12. Jayashankar S, Bagga S, Phillips GC: Sweet pepper (Capsicum annuum) transformation using Agrobacterium rhizogenes. HortScience 1997, 32:454

13. Fecker LF, Ruegenhagen $C$, Berlin J: Increased production of cadaverine and anabasine in hairy root cultures of Nicotiana tabacum expressing a bacterial lysine decarboxylase gene. Plant Mol Biol 1993, 23:11-21.

14. Sevon N, Oksman-Caldentey KM: Agrobacterium rhizogenes mediates transformation: root cultures as a source of alkaloids. Planta Med 2002, 68:859-868

15. Arfaoui A, Sifi B, Hassni E, Hadrami E, Boudabous A, Cherif M: Biochemical analysis of chickpea protection against Fusarium wilt afforded by two Rhizobium isolates. Plant Pathol 2005, 4:35-42.

16. Sekiguichi S, Yamakawa T, Kodama T, Smith SM, Yeoman MM: Establishment of hairy root cultures of chili pepper (Capsicum frutescens). Plant Tissue Cult Lett 1996, 13(2):219-221.

17. Zhi-Bi H, Min D: Hairy root and its application in plant genetic engineering J Integr Plant Biol 2006, 48(2):121-127. 
18. Hasnat R, Abbasi NA, Hafiz IA, Ahmad T, Chudhary Z: Effect of different bacterial dilutions on transformation efficiency of hot chilli (Capsicum frutescens L.) varieties. Pakistan J Bot 2008, 40:2655-2662

19. Lee YH, Kim HS, Kim JY, Jung M, Park YS, Lee JS: A new selection method for pepper transformation: callus-mediated shoot formation. Plant Cell Rep 2004, 23:50-58.

20. Saleh NM, Thuc LV: Assessment of hairy roots induction in Solenostemon scutellarioides leaves by different strains of Agrobacterium rhizogenes. Afr J Biotechnol 2009, 15:3519-3520.

21. Jeon JM, Ahn NY, Son BH, Kim CY, Han CD, Kim GD: Efficient transient expression and transformation of PEG-mediated gene uptake into mesophyll protoplasts of pepper (Capsicum annuum L.). Plant Cell Tissue Organ Cult 2007, 88:225-232.

22. Karmarkar SH, Keshavachandran R, Nazeem PA, Girija D: Hairy root induction in adapathiyan (holostemma ada-kodien k. Schum.). J Trop Agr 2001, 39:102-107.

23. Kim YS, Soh WY: Amyloplast distribution in hairy roots induced by infection with Agrobacterium rhizogenes. Biol Sci Space 1996, 10(2):102-104.

24. Porter JR, Hector F: Host range and implications of plant infection by Agrobacterium rhizogenes. Plant Sci 1991, 10(4):387-421.

25. Winans SC: Two-way chemical signaling in Agrobacterium-plant interaction. Microbiol Rev 1992, 51:12-31.

26. Hashem EA: Estimation of the endogenous auxins and cytokinins in hairy roots incited on Solanum dulcamara plants by Ri plasmid of Agrobacterium rhizogenes. Aust J Basic Appl Sci 2009, 3(1):142-147.

27. Li D, Zhao K, Xie B, Zhang B, Luo K: Establishment of a highly efficient transformation system for pepper (Capsicum annuum L.). Plant Cell Rep 2003, 21:785-788.

28. Falasca G, Reverberi M, Lauri P, Caboni E, Stradis AD, Altamura MM: How Agrobacterium rhizogenes triggers de novo root formation in a recalcitrant woody plant: an integrated histological, ultra structural and molecular analysis. New Phytologist 2002, 145:77-93.

29. Lodhi AH, Bongaerts RJM, Verpoorte R, Coomber SA, Charlwood BV: Expression of bacterial isochorismate synthase in transgenic root cultures of Rubia peregrina. Plant Cell Reprod 1996, 15:54-57.

30. Van Doorn WG, Beers EP, Dangl JL, Franklin-Tong VE: Morphological classification of plant cell deaths. Nature 2011, 1:1-6.

31. Tsong AY, Shyi DY, Jiu SY: Effects of carbenicillin and cefotaxime on callus growth and somatic embryogenesis from adventitious roots of papaya. Bot Bull Acad Sin 2001, 42:281-286.

32. Muhammad Z, Zarrin FR, Riaz UR, Chaudhary MF: Agrobacterium mediated transformation of soybean (Glycine max I.): some conditions standardization. Pakistan J Bot 2010, 42(4):2269-2279.

33. Konstantin V, Kiseleva C, Mikhail L, Kusaykin B, Alexandra S: The rol C gene induces expression of a pathogenesis-related $\beta-1,3$-glucanase in transformed ginseng cells. Phytochemistry 2006, 67(20):2225-2231.

34. Rhodes MJC, Robins RJ, Hamill JD, Parr AJ, Hilton MH, Walton NJ: Properties of transformed root culture. Phytochem Soc Eur 1990, 1:201-225.

35. Su YH, Liu YB, Zhang XS: Auxin-Cytokinin interaction regulates meristem development. Mol Plant 2011, 4(4):616-625.

36. Tien-li S, Pauline MD: Root hairiness: effect on fluid flow and oxygen transfer in hairy root cultures. J Biotechnol 2000, 83:199-210.

37. Maurel C, Barbier-Brygoo H, Spena A, Tempe J, Guern J: Single rol genes from the Agrobacterium rhizogenes TL-DNA alter some of the cellular responses to auxin in Nicotiana tabacum. Plant Physiol 1991, 97:212-216.

doi:10.1186/1756-0500-7-414

Cite this article as: Md Setamam et al: Induction of hairy roots by various strains of Agrobacterium rhizogenes in different types of Capsicum species explants. BMC Research Notes 2014 7:414.

\section{Submit your next manuscript to BioMed Central and take full advantage of:}

- Convenient online submission

- Thorough peer review

- No space constraints or color figure charges

- Immediate publication on acceptance

- Inclusion in PubMed, CAS, Scopus and Google Scholar

- Research which is freely available for redistribution

Submit your manuscript at www.biomedcentral.com/submit
Ciomed Central 